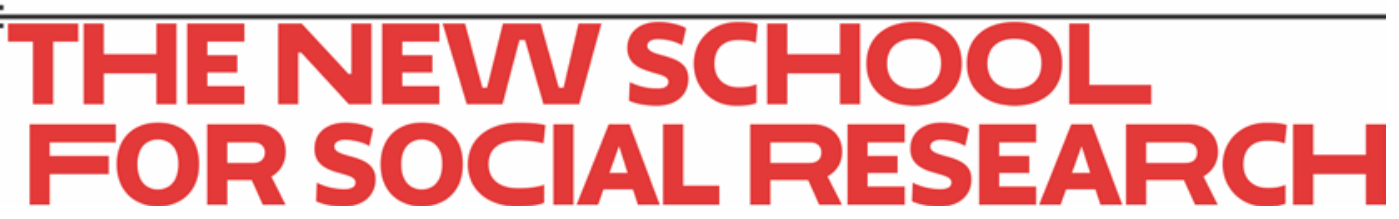

Mark Setterfield

\title{
Time variation in the size of the multiplier: a Kalecki-Harrod approach
}

September 2015

Working Paper 22/2015

Department of Economics

The New School for Social Research 


\title{
Time variation in the size of the multiplier: a Kalecki-Harrod approach
}

\author{
Mark Setterfield* \\ September 18, 2015 \\ Revised January 4, 2017
}

\begin{abstract}
A growing empirical literature demonstrates that the size of the expenditure multiplier varies over time, being both larger and consistently greater than one during periods of slow growth and/or recession. This paper contributes to the theory of the time-varying multiplier. It is shown that a combination of Kalecki's dynamic theory of investment and Harrod's "satisficing" approach to the investment decision furnish a theory in which the "crowding in" of investment expenditures following an initial demand stimulus (fiscal or otherwise) gives rise to an elevated expenditure multiplier during times of pronounced macroeconomic distress.
\end{abstract}

JEL codes: E11, E12, E22, E32

Keywords: Multiplier, investment, crowding in, Kalecki, Harrod

\section{Introduction}

According to a growing empirical literature, the expenditure multiplier must be regarded as a time-varying phenomenon that is substantially larger during periods of slow growth and/or recessions than during periods of faster growth and expansions. Studies of US macro data typically suggest a multiplier that is somewhere between two and five times larger in a low growth/recessionary environment than in a high growth/expansionary environment, and consistently larger than one (Mittnik and Semmler, 2012; Auerbach and Gorodnichenko,

\footnotetext{
${ }^{*}$ Professor of Economics, New School for Social Research; mark.setterfield@newschool.edu
} 
2012, 2013; Candelon and Lieb, 2013; Fazzari et al., 2015; Arin et al., 2015).1 According to Caggiano et al. (2015), these differences in the size of the multiplier are particularly pronounced when deep recessions are contrasted with strong upswings.

The size of the expenditure multiplier obviously depends on the actual level of real output relative to capacity, and hence the ability of the economy to accommodate changes in aggregate demand through quantity adjustments rather than price adjustments in the short run. In a Keynesian economy, however, actual output is expected to fluctuate around average levels that are consistently below potential, without displaying any automatic tendency to converge towards the time-path of potential output. In such an economy, the key to understanding time-variation in the size of the multiplier must lie in intrinsic features of the demand-formation process, rather than a periodic incapacity of the economy to accommodate fluctuations in spending through quantity adjustments.

One simple explanation for time-variation in the size of the multiplier concerns macroeconomic policy co-ordination. Christiano et al. (2011), for example, argue that the size of the multiplier in response to a fiscal stimulus depends on the response of monetary policy. If, following a demand stimulus, the central bank is concerned about an overheating economy and raises the interest rate, the multiplier will be smaller as a result. As evidenced by monetary policy in the US since the onset of the Great Recession, however, this response is less likely in a severe and/or prolonged downturn, as a result of which the multiplier will be correspondingly larger (see also Stiglitz (2014, p.16)).

Private sector responses to different macroeconomic conditions may also influence the size of the multiplier. Charles et al. (2015) develop a theory of time variation in the size of the multiplier that hinges on changes in the saving rate and its impact on the process of demand formation. The key insight in this paper derives from application of the relative

\footnotetext{
${ }^{1}$ See Charles et al. (2015, pp.254-5) for a brief survey of similar empirical studies of the multiplier in other advanced economies.
} 
income hypothesis associated with Duesenberry (1949). Hence according to Charles et al. (2015), whereas propensities to save are typically held constant in structuralist-Keynesian macro models, low growth or falling incomes may, in fact, induce rentiers - who demonstrably out-save other members of society (Taylor et al., 2014; Saez and Zucman, 2014) $)^{2}$ - to reduce their propensity to save in order to maintain consumption at levels commensurate with those achieved in the past. This will enhance the total expansion of expenditure and output associated with any given initial increase in spending - i.e., increase the size of the multiplier relative to what would be observed in a high growth, expansionary environment. Meanwhile, Palley (2009) and Charles (2016) suggest that variations in the size of the multiplier can be associated with variations in the size of the propensity to import. Specifically, as income falls during a recession, the composition of expenditures changes. Investment spending - which has a relatively large import component - falls more than other components of domestic expenditure, resulting in a decline in imports that is proportionally larger than the fall in income. This reduces the propensity to import and so raises the value of the multiplier ${ }^{3}$ Finally, Canzoneri et al. (2016) show that interest rate spreads are not only larger during recessions, but are also more responsive to fiscal expansions. The result is that an increase in government spending of any given size will be associated with a more aggressive decline in interest rate spreads during a downturn, giving rise to a larger increase in output and hence a larger (fiscal) multiplier than would be observed during a boom.

In what follows, attention is also focused on private-sector behaviour (rather than public policy co-ordination) as an explanation of time variation in the size of the multiplier. Unlike

\footnotetext{
${ }^{2}$ Saez and Zucman (2014 pp.30-31) calculate saving rates so as to include all savings made by households, both directly and indirectly (through the corporations they own). Their calculations suggest that in the US over the course of the past century, the top $1 \%$ of wealth owners saved, on average, $20-25 \%$ of their income while the bottom $90 \%$ saved just $3 \%$ of their income.

${ }^{3}$ Related to this analysis, Palley (2002) posits a pro-cyclical propensity to import based on a sectoral bottlenecks hypothesis, according to which the progressive (sector by sector) tightening of the economy during an expansion will divert an ever-larger proportion of expenditures towards imports in the course of a boom. During a recession, then, we would expect to observe a smaller propensity to import and hence a larger expenditure multiplier.
} 
Palley (2009), Charles et al. (2015), Charles (2016), and Canzoneri et al. (2016), however, it is investment spending by firms (rather than saving behaviour, financial sector behaviour, or the propensity to import) that is subject to scrutiny. Following Kalecki (1936) and Harrod (1973), particular attention is paid to the responses of expectations and investment spending - both of which are usually treated as exogenous in simple, stylized accounts of the multiplier process - to an initial demand stimulus (of whatever source), and the implications of these responses for the size of the multiplier. Ultimately we show that given the feasibility of accommodating demand expansion through quantity adjustments (i.e., assuming that the economy is not operating at capacity), variability in the size of the multiplier can arise from a mixture of Kalecki's dynamic theory of investment and Harrod's "satisficing" approach to the revision of investment decision making, which together furnish a theory of the variable crowding in of investment spending in response to an initial demand stimulus [ $^{4}$

The remainder of the paper is organized as follows. The next section draws attention to claims about the responsiveness of expectations and investment spending to prior variations in aggregate demand and output in the work of Kalecki and Harrod. In the following section, a simple model is developed to demonstrate the potential implications of these processes for the size of the expenditure multiplier. A final section concludes.

\section{Kalecki and Harrod on investment and expectations}

In his 1936 review of Keynes' General Theory (Kalecki, 1936, Targetti and Kinda-Hass, 1982):5 Kalecki argues that the General Theory consists of two fundamental parts: the

\footnotetext{
${ }^{4}$ See, for example, Field (2011) for a supply-side complement to the demand-side crowding in theory developed in this paper. According to Field (2011), public investment in infrastructure induces private investment as a result of the fact that public and private capital are complementary inputs in the production process. See also Ramirez (2004, 2006, 2008), Ramirez and Nazmi (2003), and Ramirez and Kömüves (2014) for extensive econometric verification of this hypothesis for a variety of developing and transitional economies.

${ }^{5}$ The discussion in what follows is based on the English translation of Kalecki's review due to Targetti and Kinda-Hass (1982). See also Szymborska and Toporowski (2015) for discussion of Kalecki's review of the General Theory.
} 
determination of short-run equilibrium output, based on the level of investment; and the determination of the level of investment itself. He argues that while Keynes' analysis of output determination (the principle of effective demand) is sound, his (Keynes's) analysis of the determinants of investment is flawed. The essence of Kalecki's objections to Keynes' treatment of investment is that it constitutes "an approach which is basically static to a matter which is by its nature dynamic" (Targetti and Kinda-Hass, 1982, p.252) ${ }^{6}$ Assume an increase in investment spending in response to improved expectations that, in the first instance, increase the marginal efficiency of capital above the prevailing rate of interest $]^{7}$ Keynes, Kalecki argues, suggests that this increase in investment spending will result in an increase in output. According to Kalecki, however, this is not the end of the process. As a result of the increase in output:

expectations will become more optimistic and a difference between the marginal efficiency of investment and the rate of interest will arise again. 'Equilibrium' then is not reached and the growth of investment will still persist (we are dealing here, as easily can be seen, with a Wicksellian cumulative process). (Targetti and Kinda-Hass, 1982 , p.252)

This can be expected because, as Keynes himself argues in the General Theory, in a decision making environment characterized by fundamentally uncertainty, long-term expectations are heavily influenced by events in the present and recent past. The upshot is that for Kalecki, "Keynes ... does not take sufficient account of the influence of current profitability on investment" (Targetti and Kinda-Hass, 1982, p.250; emphasis in original), as a result of

\footnotetext{
${ }^{6}$ See Lopez and Mott (1999) on this and various other points of disagreement between Kalecki and Keynes regarding the theory of investment.

${ }^{7}$ The initial difference between the marginal efficiency of capital and the rate of interest will not persist if, following Keynes, an increase in investment spending bids up the supply-price of capital causing the marginal efficiency of capital to decline until it is once again equated with the interest rate. Ceteris paribus, the improvement in expectations posited above will therefore cause a once-over increase in the level of investment spending.
} 
which he overlooks the cumulative expansion of output and investment based on the crowding in of investment expenditures triggered by an initial increase in investment spending (or for that matter, an initial increase in any component of autonomous demand). The upshot of all this is that "initial investment decisions will rarely yield an equal level of actual investment ... and that therefore any short-period equilibrium is bound to move from period to period" (Szymborska and Toporowski, 2015, p.112).8

It is clear from the context that as articulated by Kalecki, the dynamic theory of investment involves an increase in investment spending resulting in an increase in actual profitability and hence an increase in expected profitability, stimulating a further increase in investment spending, and so on. In fact, this interaction is successfully captured by the process of disequilibrium adjustment in modern Kaleckian growth theory (see, for example, Lavoie (2014, chpt. 6)). Hence in contemporary Kaleckian growth models, an initial increase in investment spending will induce successive increases in actual and hence expected profitability that, in turn, induce increases in the quantity invested - so that the final change in investment spending (once equilibrium has been restored) is larger than the initial change. But further to this interaction between current actual and expected future profitability, Kalecki's reference to optimism in his critique of Keynes calls attention to a second channel through which his dynamic theory of investment is likely to work. This channel emanates from the two-step nature of decision making under fundamental uncertainty, in which decisions are based on both a best possible forecast (the proximate focus of Kalecki's attention in his review of Keynes) and the credence of or confidence placed in these expectations (Gerrard, 1995). As argued by Dequech (1999), the decision maker's "optimistic disposition" or

\footnotetext{
${ }^{8}$ Whether or not the cumulative process that is unleashed by the initial increase in investment spending will eventually resolve into a final position of equilibrium - a point on which Kalecki appears to express scepticism - depends on whether or not the dynamic interaction of investment and output that Kalecki describes is damped. As will become clear in the next section, it is quite possible to harness the spirit of Kalecki's dynamic theory of investment without abandoning appeal to equilibrium as an organizing concept for analysis of the macroeconomic system within which this theory is embedded.
} 
"animal spirits" affects both of these components of the decision making process, impacting positively on both the forecast itself and (by reducing uncertainty aversion and/or awareness) the decision maker's confidence in this forecast. While animal spirits feature in the canonical Kaleckian growth model, changes in behaviour resulting from changes in animal spirits are not captured by the adjustment dynamics of this model, in which animal spirits are taken as given. With suitable amendment of the investment function, however, it is possible to introduce a channel of adjustment through which changes in actual outcomes relative to expected outcomes affect animal spirits, and so alter decision making independently of the direct effect on behaviour of changes in outcomes and hence expectations themselves (Setterfield, 2003, Setterfield and Budd, 2011; Setterfield and Gouri Suresh, 2015). The result is a Kaleckian model of "shifting equilibrium" (Kregel, 1976), in which revisions of animal spirits induced by changes in actual relative to expected outcomes capture the second channel of adjustment in Kalecki's dynamic theory of investment alluded to above.

This does not mean, however, that any and all revision of expectations can be expected to stimulate changes in animal spirits 9 It is at this point that the contributions of Harrod 1939, 1948, 1973) become relevant for the discussion. Of particular importance is a feature of Harrod's analysis that distinguishes his instability principle from the (in)famous "knife edge" property attributed to it by Solow (1956) (on which see also see Asimakopulos 1991, pp.161-4) and Halsmayer and Hoover (2015)). As recounted by Asimakopulos (1991, pp.161), a subtle but important qualification to the operation of the instability principle involves the reaction time required for firms to respond to discrepancies between actual and expected events. For Harrod (1939), departures of the actual from the warranted rate of growth that

\footnotetext{
${ }^{9}$ It should also be noted that the direct relationship between autonomous spending and animal spirits (via the disappointment of expectations) posited above cannot always be taken for granted. For instance, the precise source of a change in autonomous demand may influence its subsequent effect on animal spirits. Hence according to Considine and Duffy (2016), Keynes was concerned that an expansion of government spending could, in and of itself, diminish animal spirits, causing psychological crowding out (rather than crowding in). They note, however, that Keynes associated this result with a "confused psychology" on the part of the private sector and did not expect it to dominate.
} 
do not exceed the reaction time (six months) will not trigger changes in investment behavior. By the time of his reply to Robinson (1970), Harrod (1970) had expanded upon this theme, arguing that the size (as well as the duration) of discrepancies between actual and expected outcomes plays a central role in the operation of the instability principle, which is therefore less like a "knife edge" than a "shallow dome". Hence in his final book on the subject, Harrod argues that:

if they [deviations of the actual form the warranted rate] are of moderate dimensions, I would not suppose that they would bring the instability principle into operation. That is why I so much object to the knife-edge idea. It requires a fairly large deviation ... to bring the instability into play. (Harrod, 1973, p.33)

The investment behaviour envisaged by Harrod bears comparison to a satisficing heuristic of the sort envisaged by Simon (1955, 1956), in which explicit acknowledgment of the limits to their foresight means that firms are unlikely to be provoked into behavioural change by only modest and/or brief discrepancies between expectations and actual events. Instead of adjustment resting on a "knife edge" created by a point estimate of the likely future value of some variable, a rule of thumb is developed that specifies a tolerable interval of error around the point estimate. Deviations in actual outcomes from expected events that lie outside this tolerable interval will attract attention and provoke behavioural change. Expectational error within the bounds prescribed by the interval will, however, be ignored. More generally, Harrod's thinking suggests that investment behaviour is unlikely to vary continuously, but is instead susceptible to discrete variation depending on where macroeconomic outcomes lie with respect to the boundaries of conventionally-defined tolerable intervals around any expected, normal, or target value of a variable that is used to guide behaviour in an environment of uncertainty.

\footnotetext{
${ }^{10}$ In Harrod (1973, p.32), the preferred metaphor for the instability principle is a "grassy slope" rather than a "shallow dome".
} 
What are the implications of these ideas for the multiplier?11 The main claim advanced here, and developed in detail in the following section, is that a mixture of Kalecki's dynamic theory of investment and Harrod's "satisficing" approach to the revision of investment decisions provides a basis for understanding time variation in the multiplier, working through the contribution of investment spending to the process of demand formation.

\section{A simple model}

We begin with a simple Kaleckian model of the form: ${ }^{12}$

$$
\begin{gathered}
g=\alpha+\gamma r \\
r=\frac{1}{s_{\pi}} g
\end{gathered}
$$

where $g$ is the rate of accumulation and hence growth 13 denotes animal spirits, $r$ is the rate of profit, and $s_{\pi}$ is the propensity to save out of profits (assumed constant). Next, we augment the model with an animal spirits reaction function of the form:

$$
\dot{\alpha}=\left(\alpha_{1}+\alpha_{2}\right)\left(g-g^{e}\right)
$$

\footnotetext{
${ }^{11}$ It is interesting to note that although he explicitly discusses the multiplier concept in his (approving) discussion of Keynes' theory of equilibrium output determination, Kalecki does not attempt to explicitly spell out the implications of his dynamic theory of investment for the multiplier.

${ }^{12}$ The explicit accelerator term characteristic of the canonical Kaleckian investment function is omitted for simplicity. Note, however, that if capacity utilization $(u)$ is assumed variable, and given that $r=\pi u$ (where $\pi$ is the profit share of income), then the standard Kaleckian stagnationist result obtains from the model here. Hence it follows from equations (1) and (2) that:

$$
\begin{gathered}
u=\frac{\alpha}{\left(s_{\pi}-\gamma\right) \pi} \\
\Rightarrow \frac{d u}{d \pi}=\frac{-\alpha\left(s_{\pi}-\gamma\right)}{\left(\left[s_{\pi}-\gamma\right] \pi\right)^{2}}<0
\end{gathered}
$$

given that $s_{\pi}>\gamma$ by the Keynesian stability condition.

${ }^{13}$ We assume a fixed full-capacity capital to output ratio, which implies that the rate of accumulation $g=I / K$ is equivalent to the rate of growth of output. In the context of this paper, $g$ should be thought of as denoting the short-term rate of growth.
} 
where $g^{e}$ is the expected rate of growth. In light of the interpretation of Kalecki's dynamic theory of investment advanced in the previous section, this reaction function can be thought of as having a distinct Kaleckian pedigree, in so far as $g>g^{e}$ will lead to an improvement in animal spirits which will, in turn (via equation (1)), affect investment spending. Critical to the behaviour of $\alpha$ in equation (3) is the parameter $\alpha_{2}$, which is signed as follows:

$$
\begin{aligned}
& \alpha_{2}>0 \text { if }\left|g-g_{n}\right|>c \\
& \alpha_{2}=0 \text { if }\left|g-g_{n}\right| \leq c
\end{aligned}
$$

where $g_{n}$ is the (exogenously given) normal rate of growth that firms associate with longterm, secular trends in the economy, and $c$ is a conventional constant, the value of which is taken as given. This treatment of $\alpha_{2}$ gives the model a Harrodian pedigree by introducing discontinuity into the adjustment of $\alpha$ in equation (3) reminiscent of the discrete behavioural variation to which Harrod appealed in his defence of the instability principle. In this case, the extent to which adjustments of expectations give rise to changes in animal spirits varies discretely, depending on the proximity of the actual rate of growth to its normal value. Hence with $\alpha_{1}>0$ and in the spirit of Kalecki, some crowding in of investment through induced changes in animal spirits is always permitted in equation (3) whenever $g \neq g^{e}$. But in the spirit of Harrod, the degree to which crowding in occurs is elevated whenever, together with $g \neq g^{e}$, the actual rate of growth is deemed sufficiently "far from trend" $\left(\left|g-g_{n}\right|>c\right)$ by firms ${ }^{14}$ Intuitively, equations (4) and (5) suggest that the revision of animal spirits in (3) will be subject to an additional "euphoria effect" if growth finally exceeds expectations following a particularly severe slump, motivating a sense that the "worst is finally over".

The model outlined above is extremely simple, but suffices to illustrate how Kaleckian and

\footnotetext{
${ }^{14}$ Note that this involves no loss of generality: a more strictly Harrodian interpretation of adjustments could be imposed by setting $\alpha_{1}=0$ without affecting the results that follow.
} 
Harrodian insights into the determination of investment spending can combine to produce a time-varying multiplier - specifically, a multiplier that is larger during times of pronounced macroeconomic distress ${ }^{15}$ Solving equations (1) and (2) yields:

$$
g=\frac{s_{\pi} \alpha}{s_{\pi}-\gamma}
$$

from which it follows that:

$$
\dot{g}=\frac{s_{\pi}}{s_{\pi}-\gamma} \dot{\alpha}
$$

Substituting equation (3) into this last expression, we then arrive at:

$$
\dot{g}=\frac{s_{\pi}}{s_{\pi}-\gamma}\left(\alpha_{1}+\alpha_{2}\right)\left(g-g^{e}\right)
$$

Finally, we complete our model by assuming that expectations adjust adaptively as:

$$
\dot{g}^{e}=\beta\left(g-g^{e}\right)
$$

In equations (7) and (8), $g=g^{e} \Longleftrightarrow \dot{g}=\dot{g}^{e}=0$. Under these conditions the system is in equilibrium, with the equilibrium rate of growth given by the expression in equation (6). Taken together with equations (4) and (5), equation (7) describes the response of the short-term growth rate to any initial disequilibrating perturbation that renders $g \neq g^{e}$, while equation (8) describes the response of short-term growth expectations to the same event. The system comprising equations (7) and (8) is stable as long as $\frac{s_{\pi}}{s_{\pi}-\gamma}\left(\alpha_{1}+\alpha_{2}\right)<\beta$ - intuitively,

\footnotetext{
${ }^{15}$ It should be noted, of course, that the simplicity of the model means that various "other things" (implicitly) remain "equal" that may, in fact, thwart the result that follows. These include, for example, de-leveraging efforts by debtor units in the economy, and the effects of elevated liquidity preference on savings rates - either of which might serve to diminish the size of the multiplier during times of severe macroeconomic distress. The reader is reminded, however, that empirical evidence suggests that on balance, the multiplier is larger during periods of slower growth, and particularly during deep recessions (Caggiano et al. 2015).
} 
as long as there is faster adjustment of $g^{e}$ than $g$ in response to $g^{e} \neq g$ so as to ensure that any gap between these two variables always closes (rather than widens) over time 16

Now consider a shock to the system that increases $g$ such that $g>g^{e}$. Two scenarios can unfold in response to this situation. First, suppose that the initial equilibrium rate of growth was "far from trend", such that $g-g_{n}>c$ and hence $\alpha_{2}>0$. In this situation, the dynamics of $g$ will correspond to those found in equation (7) - at least initially. Since $g$ is rising as a result of equation (7), the possibility exists that by some time period $\tau$ prior to the re-establishment of equilibrium conditions $g=g^{e}$, we will observe $g-g_{n} \leq c$ and hence $\alpha_{2}=0$. In this case, the system will subsequently (i.e., during time period $\tau$ and thereafter) exhibit the modified dynamics:

$$
\dot{g}=\frac{s_{\pi}}{s_{\pi}-\gamma}\left(\alpha_{1}\right)\left(g-g^{e}\right)
$$

Now suppose that the initial equilibrium rate of growth prior to the shock resulting in $g>g^{e}$ was "near to trend", such that $g-g_{n} \leq c$ and hence $\alpha_{2}=0$. In this situation, the behavior of $g$ will only ever correspond to the modified dynamics described by equation (9).

The implications of all this are straightforward: over any given time horizon, $n$, the value of $\int_{i=1}^{n} \dot{g}_{i} d t$ will always be larger in the first scenario than in the second. To see this explicitly, denote the two scenarios outlined above, in which the initial rate of growth is either "far from trend" or "near to trend", as scenarios A and B, respectively. Note that given the definition of $\tau$ above, $\tau-1$ denotes the number of periods for which $g-g_{n}>c$ and hence $\alpha_{2}>0$ in scenario A. It follows from equations (7) and (9) (which govern the values of $g_{A i}$ and $\dot{g}_{B i}$ for $\left.i=1, \ldots, \tau-1\right)$ that:

\footnotetext{
${ }^{16}$ This result is demonstrated formally in the appendix to this paper. Recall that in his review of Keynes, Kalecki alludes to a "Wicksellian cumulative process" when summarizing the effects of his dynamic theory of investment. This suggests that there may be circumstances under which the stability condition identified above does not hold.
} 


$$
\int_{i=1}^{\tau-1} \dot{g_{A i}} d t>\int_{i=1}^{\tau-1} \dot{g_{B i}}
$$

Since $g-g_{n} \leq c$ and hence $\alpha_{2}=0$ for $i \geq \tau$ in scenario A, so that the value of $\dot{g}$ is governed by equation (9) in both scenarios for $i \geq \tau$ ( $\operatorname{such}$ that $\dot{g}_{A i}=\dot{g}_{B i}$ for $i \geq \tau$ ), it must be that:

$$
\int_{i=1}^{n} g_{A i} d t>\int_{i=1}^{n} \dot{g}_{B i}
$$

for any $n$. In other words, we will observe a larger total change in the equilibrium growth rate in response to an initial demand stimulus of any given size - i.e., a larger expenditure multiplier - in scenario A. ${ }^{17}$ Ultimately, this is because of the implications of the state of current economic conditions (relative to trend) for the crowding in of investment expenditures and hence the demand-formation process.

\section{Conclusions}

The size of current output relative to available capacity is, of course, a crucial determinant of the very possibility that the economy will respond to a demand stimulus through the Keynesian quantity-adjustment channel. But in a Keynesian economy in which the capacity constraint of potential output is seldom binding, it is factors intrinsic to the process of demand-formation to which we must appeal in order to explain time-variation in the size of the expenditure multiplier.

This paper shows that the observation of larger multipliers during periods of low growth and/or recession can be explained by appeal to Kalecki's dynamic theory of investment coupled with the discrete variations in investment behaviour to which Harrod appealed in his defence of the instability principle. Together, these ideas furnish a theory of the variable

\footnotetext{
${ }^{17}$ The conditions of supply must, of course, be physically capable of accommodating the changes in output posited: there is no suggestion here that the economy can somehow exceed its physical supply capacity.
} 
crowding in of investment expenditures, operating through the interaction of disappointed short-term expectations and animal spirits, in which the crowding in effect is enhanced following a demand stimulus applied in the midst of pronounced macroeconomic distress. This theory of the time-varying multiplier explains the marked contrast between the size of the multiplier during deep recessions relative to its value during strong upswings, as observed by Caggiano et al. (2015).

It is important to note that the theory of a time-varying multiplier developed in this paper is perfectly consistent with existing theories of the same phenomenon based on policy co-ordination effects (Christiano et al., 2011) and variations in other aspects of private sector behaviour (Palley, 2009; Charles et al., 2015; Charles, 2016; Canzoneri et al., 2016). In other words, these various theories are not mutually exclusive, so that some combination of them may be responsible for explaining observed variations in the size of the multiplier over time. This suggests that at the current juncture, the most important issue for empirical studies of the multiplier process is not whether but why the multiplier is time-varying over any particular historical interval.

\section{Appendix A Stability}

Formally, the Jacobian of the system of equations (7) and (8) can be written as:

$$
\mathbf{J}=\left[\begin{array}{rr}
\frac{s_{\pi}}{s_{\pi}-\gamma}\left(\alpha_{1}+\alpha_{2}\right) & \frac{s_{\pi}}{s_{\pi}-\gamma}\left(\alpha_{1}+\alpha_{2}\right) \\
\beta & \beta
\end{array}\right]
$$

from which it follows that $\operatorname{Det}(\mathbf{J})=0$ and $\operatorname{Tr}(\mathbf{J})=\frac{s_{\pi}}{s_{\pi}-\gamma}\left(\alpha_{1}+\alpha_{2}\right)-\beta<0$ iff $\beta>\frac{s_{\pi}}{s_{\pi}-\gamma}\left(\alpha_{1}+\right.$ $\left.\alpha_{2}\right)$. The sign of $\operatorname{Tr}(\mathbf{J})$ ensures stability of the system, the singularity of $\mathbf{J}(\boldsymbol{D e t}(\mathbf{J})=0)$ implying that the equilibrium of the system is indeterminate. This last result is, of course, a consequence of the fact that equations (7) and (8) together give rise only to the general 
description of equilibrium $g=g^{e}$. As noted in the text, the exact equilibrium rate of growth that will obtain at any point in time is described by equation (6), and will, of course, depend on the exact value of the animal spirits term, $\alpha$, that is generated (as a result of the operation of equation (3p) by the sequence of disequilibrium adjustments that lead the economy towards equilibrium.

\section{References}

Arin, K., F. Koray, and N. Spagnolo (2015). Fiscal multipliers in good times and bad times. Journal of Macroeconomics 44(C), 303-311.

Asimakopulos, A. (1991). Keynes's General Theory and Accumulation. Cambridge: Cambridge University Press.

Auerbach, A. and Y. Gorodnichenko (2012). Measuring the output responses to fiscal policy. American Economic Journal: Economic Policy 4(2), 1-27.

Auerbach, A. J. and Y. Gorodnichenko (2013). Corrigendum: Measuring the Output Responses to Fiscal Policy. American Economic Journal: Economic Policy 5(3), 320-22.

Caggiano, G., E. Castelnuovo, V. Colombo, and G. Nodari (2015). Estimating fiscal multipliers: News from a non-linear world. The Economic Journal 125(584), 746-776.

Candelon, B. and L. Lieb (2013). Fiscal policy in good and bad times. Journal of Economic Dynamics and Control 37(12), 2679-2694.

Canzoneri, M., F. Collard, H. Dellas, and B. Diba (2016). Fiscal multipliers in recessions. Economic Journal 126(590), 75-108.

Charles, S. (2016). An additional explanation for the variable Keynesian multiplier: The role of the propensity to import. Journal of Post Keynesian Economics 39(2), 187-205.

Charles, S., T. Dallery, and J. Marie (2015). Why the Keynesian multiplier increases during hard times: A theoretical explanation based on rentiers' saving behaviour. Metroeconomica $66(3), 451-473$.

Christiano, L., M. Eichenbaum, and S. Rebelo (2011). When Is the Government Spending Multiplier Large? Journal of Political Economy 119(1), 78 - 121.

Considine, J. and D. Duffy (2016). Keynes and the confidence faeries. Cambridge Journal of Economics 40(1), 309-325. 
Dequech, D. (1999). Expectations and confidence under uncertainty. Journal of Post Keynesian Economics 21(3), 415-430.

Duesenberry, J. S. (1949). Income, Saving and the Theory of Consumer Behaviors. Cambridge, MA: Harvard University Press.

Fazzari, S., J. Morley, and I. Panovska (2015). State-dependent effects of fiscal policy. Studies in Nonlinear Dynamics 85 Econometrics 19(3), 285-315.

Field, A. (2011). A Great Leap Forward: 1930s Depression and U.S. Economic Growth. New Haven, CT: Yale University Press.

Gerrard, B. (1995). Probability, uncertainty and behaviour: a Keynesian perspective,. In S. Dow and J. Hillard (Eds.), Keynes, Knowledge and Uncertainty. Aldershot: Edward Elgar.

Halsmayer, V. and K. D. Hoover (2015). Solow's Harrod: Transforming macroeconomic dynamics into a model of long-run growth. The European Journal of the History of Economic Thought DOI: 10.1080/09672567.2014.1001763.

Harrod, R. (1939). An essay in dynamic theory. Economic Journal 49(193), 14-33.

Harrod, R. F. (1948). Towards a Dynamic Economics. London: Macmillan.

Harrod, R. F. (1970). Harrod after twenty-one years: a comment. Economic Journal 80(319), $737-41$.

Harrod, R. F. (1973). Economic Dynamics. London: Macmillan.

Kalecki, M. (1936). Pare uwag o teorii Keynesa (Some remarks on Keynes' theory). Ekonomista 3.

Kregel, J. A. (1976). Economic Methodology in the Face of Uncertainty: The Modelling Methods of Keynes and the Post-Keynesians. Economic Journal 86(342), 209-25.

Lavoie, M. (2014). Post-Keynesian Economics: New Foundations. Cheltenham: Edward Elgar.

Lopez, J. and T. Mott (1999). Kalecki versus Keynes on the determinants of investment. Review of Political Economy 11(3), 291-301.

Mittnik, S. and W. Semmler (2012). Regime dependence of the fiscal multiplier. Journal of Economic Behavior 8 Organization 83(3), 502 - 522.

Palley, T. (2002). Pitfalls in the theory of growth: an application to the balance-of-paymentsconstrained growth model. In S. M. (Ed.), The Economics of Demand-Led Growth: Challenging the Supply-Side Vision of the Long Run, pp. 115-125. Cheltenham, UK: Edward Elgar. 
Palley, T. (2009). Imports and the income-expenditure model: implications for fiscal policy and recession fighting. Journal of Post Keynesian Economics 32(2), 311-322.

Ramirez, M. (2004). Is public infrastructure spending productive in the Mexican case? a vector error correction analysis. The Journal of International Trade and Economic Development 13(2), 159-178.

Ramirez, M. (2006). Latin American investment perfomance during the 1980-2002 period: A panel cointegration approach. Applied Econometrics and International Development 6(2), $109-124$.

Ramirez, M. (2008). What explains Latin America's poor investment performance during the 1980-2001 period?: a panel unit root analysis. International Review of Applied Economics 22(1), 1-15.

Ramirez, M. and Z. Kömüves (2014). Economic infrastructure, private capital formation, and fdi inflows to Hungary: A unit root and cointegration analysis with structural breaks. Atlantic Economic Journal 42(4), 367-382.

Ramirez, M. D. and N. Nazmi (2003). Public Investment and Economic Growth in Latin America: an Empirical Test. Review of Development Economics 7(1), 115-126.

Robinson, J. (1970). Harrod after twenty-one years. Economic Journal 80(319), 731-37.

Saez, E. and G. Zucman (2014). Wealth inequality in the United States since 1913: Evidence from capitalized income tax data. Working Paper 20625, National Bureau of Economic Research.

Setterfield, M. (2003). Neo-Kaleckian growth dynamics and the state of long-run expectations: wage- versus profit-led growth reconsidered. In N. Salvadori (Ed.), Old and New Growth Theories: An Assessment. Cheltenham: Edward Elgar.

Setterfield, M. and A. Budd (2011). A Keynes-Kalecki model of cyclical growth with agentbased features. In P. Arestis (Ed.), Microeconomics, Macroeconomics and Economic Policy: Essays in Honour of Malcolm Sawyer. Palgrave Macmillan.

Setterfield, M. and S. Gouri Suresh (2015). Firm performance, macroeconomic conditions, and 'animal spirits' in a Post Keynesian model of aggregate fluctuations. Journal of Post Keynesian Economics, forthcoming.

Simon, H. (1955). A behavioral model of rational choice. Quarterly Journal of Economics 69(1), 99-118.

Simon, H. (1956). Rational choice and the structure of the environment. Psychological Review 63, 129-138. 
Solow, R. M. (1956). A contribution to the theory of economic growth. Quarterly Journal of Economic 70(1), 65-94.

Stiglitz, J. E. (2014). Reconstructing macroeconomic theory to manage economic policy. Working Paper 20517, National Bureau of Economic Research.

Szymborska, H. and J. Toporowski (2015). 'Dr Kalecki' on Mr Keynes. In J. Toporowski and L. Mamica (Eds.), Michat Kalecki in the 21st Century, pp. 108-115. London: Palgrave Macmillan.

Targetti, F. and B. Kinda-Hass (1982). Kalecki's review of Keynes' General Theory. Australian Economic Papers 21 (39), 244-260.

Taylor, L., A. Rezai, R. Kumar, N. H. Barbosa-Filho, and L. Carvalho (2014). Wage increases, transfers, and the socially determined income distribution in the usa. Technical report, Institute for New Economic Thinking Working Paper Series No. 11. 